\title{
Visual outcome and complications of cataract extraction after pars plana vitrectomy
}

This article was published in the following Dove Press journal: Clinical Ophthalmology

\section{Amanda Rey \\ Ignasi Jürgens \\ Xavier Maseras \\ Agnieszka Dyrda \\ Patricia Pera \\ Antonio Morilla}

Department of Ophthalmology, Institut Catala de Retina (ICR), Barcelona, Spain
Correspondence: Amanda Rey Institut Catala de Retina (ICR), Ganduxer, No II 7, 08022 Barcelona, Spain $\mathrm{Tel}+34932547922$

Fax +34934187857

Email amandarey1912@hotmail.com
Purpose: To evaluate the visual outcomes and complications of phacoemulsification in previously vitrectomized eyes.

Patients and methods: A retrospective analysis of 87 consecutive vitrectomized eyes ( 87 patients) which had undergone phacoemulsification with intraocular lens implantation between 2013 and 2016.

Results: The mean interval from pars plana vitrectomy (PPV) to cataract surgery (CS) was 18.8 months. Mean age at CS was 61.5 years. Intraoperative complications included anterior rhexis tear ( 1 eye) and hyphema ( 1 eye). Postoperative complications included macular edema (17.2\%, mean 42 days), posterior capsule opacification (13.8\%, mean 14 months), ocular hypertension $(11.5 \%)$, and anterior uveitis (1.1\%). Preoperative mean best-corrected visual acuity improved from $20 / 50$ to $20 / 25$. Ninety-one percent of the eyes gained 2 or more lines, and $95 \%$ achieved visual acuity $\geq 20 / 40$ after CS. Preoperative mean spherical equivalent improved from -4.35 to -0.17 . Eyes with clear lens prior to the PPV had later CS (clear lens 27.1 vs no clear lens 9.7 months; $p=0.016)$. Patients $>55$ years with clear lens at PPV $(\mathrm{n}=21)$ had earlier $\mathrm{CS}$ than younger ones with clear lens ( $\mathrm{n}=24)$ (11.8 vs 40.5 months; $p=0.033)$. Mean follow-up was 14.5 months.

Conclusion: Phacoemulsification is a safe procedure in vitrectomized eyes, with substantial gains in vision in most cases. Patients of advanced age and eyes without clear lens prior to the PPV had earlier CS.

Keywords: cataract surgery, intraocular lens, pars plana vitrectomy, vitreoretinal surgery

\section{Introduction}

An increasing number of posterior segment disorders are successfully managed with pars plana vitrectomy (PPV). These disorders include retinal detachments, macular holes, epiretinal membranes, vitreous hemorrhages or opacities, and macular hemorrhages. Cataract development is a frequent postoperative complication, with an incidence rate varying from $12.5 \%$ to $80 \% .{ }^{1-8}$ Although the exact cause of cataract formation is unclear, it has been associated with patient age, ${ }^{9,10}$ preexisting nuclear sclerosis, ${ }^{9}$ length of surgery, ${ }^{11}$ lens injury during PPV, ${ }^{12}$ prolonged exposure to an intravitreal light source, ${ }^{13}$ diabetic retinopathy, ${ }^{14,15}$ the type of infusion fluid or cannula, ${ }^{16}$ and the use of intraocular gas or silicone oil. ${ }^{4,10}$ Small-gauge PPV systems are potentially less risky than previous 20-gauge PPV systems due to reduced balanced salt solution consumption, lower intravitreal fluid flow, decreased surgical time, and ocular manipulation. ${ }^{17}$ Phacoemulsification is associated with smaller incision size, less induced astigmatism, faster visual rehabilitation, and fewer complications. With progressive improvements in vitreoretinal or cataract surgical techniques and new devices, more scientific research is now needed to monitor updated surgical outcomes after phacoemulsification in vitrectomized eyes. We report a large series 
of 87 vitrectomized eyes in which phacoemulsification with intraocular lens (IOL) implantation was performed. The primary endpoint was to describe the outcomes after cataract surgery (CS) in vitrectomized eyes. The secondary endpoint was to analyze whether the time of cataract development is related to patients' characteristics at PPV (general or ophthalmologic).

\section{Patients and methods}

Eighty-seven consecutive patients (87 eyes) with previous PPV who underwent phacoemulsification and IOL implantation between June 2013 and December 2016 were retrospectively reviewed. The protocol for this study was approved by our institution's ethics committee (Institut Catala de Retina). Written informed consent was obtained from all patients before the surgery was performed, and this consent also included the use of their medical data for research. The study and data accumulation were performed in conformity with Spanish and European laws and in adherence to the tenets of the Declaration of Helsinki.

The data regarding the patient demographics, indication for PPV with Constellation (Alcon Laboratories, Fort Worth, TX, USA) or Stellaris (Bausch \& Lomb, Bridgewater, NJ, USA) vitrectomy system, degree of myopia, visual acuity (VA) before and at 3 months after PPV, prior crystalline lens status, type of vitreous substitute used, and the duration between PPV and phacoemulsification surgery were obtained. The preoperative evaluation before CS included age at surgery, VA, slit-lamp examination, morphology or type of cataract, and optical biometry (IOL master Carl Zeiss Meditec V.5, Carl Zeiss Meditec, Jena, Germany). Axial length was measured using immersion scan in 2 cases in which optical biometry resulted in error. Type and power of IOL used and intraoperative complications were noted. A toric monofocal IOL was placed only in cases with astigmatism greater than $1.50 \mathrm{D}$, and a trifocal IOL was placed only in eyes without previous macular pathology, normal corneal topography, normal macular optical coherence tomography (OCT), and normal visual field. CS was planned to be performed as routine phacoemulsification under topical or peribulbar anesthesia $\left(\right.$ Infinity ${ }^{\circledR}$ or Centurion ${ }^{\circledR}$ Vision System, Alcon Laboratories). All PPVs in this study were done by 4 experienced surgeons (AR, IJ, XM, and PP), and CS was done by a single surgeon (AR).

Postoperative complications and date of last follow-up after phacoemulsification were noted. VA at the last visit was recorded and compared with preoperative VA. OCT was also performed in all patients to exclude macular edema within 2 months after CS.
Crystalline lens status was determined clinically with the slit-lamp and graded as clear, trace, mild (1+), moderate $(2+)$, severe nuclear sclerosis $(3+)$, or very severe cataract when fundus was not visible (4+). ${ }^{9}$ Type of cataract included posterior subcapsular, nuclear sclerotic, and anterior cortical cataracts. ${ }^{1}$

The results were statistically analyzed using the SPSS software version 16.0 (SPSS, Inc., Chicago, IL, USA) and presented as frequency, percentage $(\%)$, and mean $\pm \mathrm{SD}$. Parametric data were compared using one-way analysis of variance and nonparametric data using Mann-Whitney test. Correlations were evaluated using the Pearson correlation coefficients and multivariate cox regression analysis. The Kaplan-Meier method and log-rank (Mantel-Cox) test were applied. A $p$-value of $<0.05$ was considered statistically significant with a confidence interval of $95 \%$.

\section{Results}

Eighty-seven eyes of 87 patients were included in the study. Demographic and ocular characteristics at PPV are shown in Table 1. Demographic and ocular characteristics at CS are shown in Table 2.

Topical anesthesia was used in 63 eyes $(72.4 \%)$, and a monofocal IOL was placed in 65 eyes (74.7\%), a toric monofocal IOL in $21(24.2 \%)$, and a trifocal IOL in only $1(1.1 \%)$. Mean power of the IOL was +18 D (range: $1-28.5$ ). The IOLs were placed successfully in the capsular bag in all cases. Intraoperative complications included anterior rhexis tear (1 eye) and hyphema (1 eye). Inadequate fundus reflex was evidenced in 2 eyes, and miosis occurred in 6 eyes ( 1 eye required iris retractors and 5 eyes intracameral phenylephrine). Postoperative complications included cystoid macular edema (CME: 15 eyes) at a mean of 42 days (range: 19-120), posterior capsule opacification (PCO) which

Table I Demographic and ocular characteristics at PPV

\begin{tabular}{ll}
\hline Demographic and ocular characteristics at PPV \\
\hline Gender & 46 women, 4 I men \\
Age & $60 \pm 8$ years (25-75) \\
Lens state & $51.7 \%$ clear lens, 29.9\% trace nuclear \\
& sclerosis, I4.9\% mild cataract (I+), \\
& $3.4 \%$ moderate cataract (2+) \\
& $44.8 \%$ (mean -5.20 D) \\
Myopia & $64.4 \%$ retinal detachment, I4.9\% macular \\
Primary indications for PPV & hole, I2.6\% epiretinal membrane, \\
& $5.7 \%$ vitreous hemorrhage, I. I\% vitreous \\
& opacities, I. I\% macular hemorrhage \\
& $79.3 \%$ \\
Gas at PPV & $20 / 63$ (hand movement to 20/20) \\
VA prior to PPV & $20 / 32$ (hand movement to 20/20) \\
VA at 3 months after PPV &
\end{tabular}

Abbreviations: PPV, pars plana vitrectomy; VA, visual acuity. 
Table 2 Demographic and ocular characteristics at CS

\begin{tabular}{ll}
\hline Demographic and ocular characteristics at CS \\
\hline Gender & 46 women, $4 \mathrm{I}$ men \\
Age & $61.5 \pm 8$ years (4I-75) \\
Mean interval from PPV to CS & 18.8 months (I-207) \\
Lens state & $75.9 \%$ moderate cataract (2+), \\
& $21.8 \%$ severe cataract (3+), \\
& $2.3 \%$ very severe cataract (4+) \\
Cataract type & $86.2 \%$ nuclear, II.5\% posterior \\
& subcapsular, $2.3 \%$ anterior \\
Mean axial length & cortical cataract \\
Mean astigmatism & $25 . I 4 \pm 2.16$ mm (2I.79-34.28) \\
Mean anterior chamber depth & $-1.17 \pm 0.89 \mathrm{D}(0$ to -4.65$)$ \\
VA prior to CS & $3.16 \pm 0.38$ mm (2.28-4.38) \\
Final VA after CS & $20 / 50$ (counting fingers to 20/25) \\
\hline
\end{tabular}

Abbreviations: CS, cataract surgery; PPV, pars plana vitrectomy; VA, visual acuity.

required Nd:YAG laser (12 eyes) at a mean of 14 months (range: 4-35), ocular hypertension (10 eyes), and anterior uveitis ( 1 eye). Ten out of the 15 eyes with postoperative CME had previous epiretinal membrane, none of these patients were diabetic, and the edema resolved after topical treatment (4 eyes), subtenon steroids ( 9 eyes), intravitreal steroids ( 1 eye), and PPV with membrane peeling ( 1 eye) (Table 3). Mean follow-up duration after CS was 14.5 months (range: 6-50).

Preoperative mean corrected distance VA improved from $20 / 50$ to $20 / 25$, with a mean increase of 4.48 Snellen lines $(p<0.001)$. Preoperative mean near corrected VA improved from 20/32 to 20/25; $p<0.001$. Preoperative mean spherical equivalent refraction improved from $-4.35 \pm 4.21 \mathrm{D}$

Table 3 Intraoperative and postoperative complications of CS

\begin{tabular}{|c|c|}
\hline Complications of CS & $\mathrm{N}=87$ eyes \\
\hline \multicolumn{2}{|l|}{ Intraoperative } \\
\hline Miosis & $6(6.9 \%)$ \\
\hline Inadequate fundus reflex & $2(2.3 \%)$ \\
\hline Hyphema & I (I.I\%) \\
\hline Anterior rhexis tear & $\mathrm{I}(\mathrm{I} . \mathrm{I} \%)$ \\
\hline $\begin{array}{l}\text { Posterior capsule rupture, zonular } \\
\text { dehiscence, or vitreous loss }\end{array}$ & $0(0 \%)$ \\
\hline \multicolumn{2}{|l|}{ Postoperative } \\
\hline CME & $15(17.2 \%)$ \\
\hline $\mathrm{PCO}$ & $12(13.8 \%)$ \\
\hline Ocular hypertension & $10(11.5 \%)$ \\
\hline Anterior uveitis & $\mathrm{I}(\mathrm{I} . \mathrm{l} \%)$ \\
\hline $\begin{array}{l}\text { Retinal detachment, endophthalmitis, } \\
\text { corneal wound leakage, reopened macular } \\
\text { hole, dislocated IOL or vitreous hemorrhage }\end{array}$ & $0(0 \%)$ \\
\hline
\end{tabular}

Abbreviations: CME, cystoids macular edema; CS, cataract surgery; IOL, intraocular lens; PCO, posterior capsule opacification. (range: -20 to +2.75$)$ to $-0.17 \pm 0.57 \mathrm{D}$ (range: -3.25 to +0.75$)$ after CS $(p<0.001)$ (Figure 1). Final VA of $20 / 40$ or better was achieved in $95 \%$ of the eyes after phacoemulsification (Table 4). In total, $25 \%$ of the patients had residual symptoms: 17 had metamorphopsia (6/17 severe), 4 diplopia ( 2 required prism correction), and 1 a central scotoma after CS.

Patients $>55$ years $(n=61)$ when undergoing PPV had earlier CS than younger patients (10.6 vs 37.7 months; $p=0.025)$. Eyes with clear lens prior to the PPV $(\mathrm{n}=45)$ had later CS than eyes with some degree of cataract (27.1 vs 9.7 months; $p=0.016$ ), (Figure 2). Eyes with gas tamponade $(n=69)$ were operated earlier than eyes without a tamponade, but the difference was not statistically significant (16.7 vs 26.2 months; $p=0.393$ ). In addition, myopia (16.9 months in myopic eyes vs 20.8 months in nonmyopic eyes; $p=0.602$ ) and axial length did not correlate with the time of the CS (Pearson correlation coefficient: $+0.189 ; p=0.116$ ). Multivariate Cox regression analysis results for CS are summarized in Table 5. Age and lens status at PPV was found to be associated with CS.

If the groups are separated by lens state prior to PPV, patients $>55$ years with clear lens at PPV $(n=21)$ had earlier CS than younger ones with clear lens $(n=24)(11.8$ vs 40.5 months; $p=0.033$ ). The Kaplan-Meier method and logrank (Mantel-Cox) test were applied to the data for patients with clear lens classified into 2 groups according to age $\leq$ or $>55$ years $(p=0.005)$ (Figure 3 ).

Eyes with clear lens at PPV operated with gas $(n=36)$ had earlier CS than eyes with clear lens at PPV in which gas was not used ( $\mathrm{n}=9)$, but this result was not statistically significant (23.6 vs 41.3 months; $p=0.416$ ). Axial length or the presence of myopia in eyes with clear lens prior to PPV did not correlate with the time of the CS after PPV (24.4 vs 29.7 months; $p=0.328$ ).

\section{Discussion}

As vitreoretinal surgical techniques and outcomes improve and indications for PPV expand, the rate of cataract extraction after PPV is increasing. In our study, we evaluated intraoperative and postoperative complications and visual outcomes after phacoemulsification in previously vitrectomized eyes. We also analyzed the mean time from CS to PPV taking into account age and lens status prior to PPV, myopia and axial length, and the use of a gas tamponade.

In our series, the mean interval from PPV to CS was 18 months, with $19 \%$ of the cataracts operated on within 6 months, $63 \%$ within 1 year, and $72 \%$ within 2 years. Our study demonstrates that the majority of postvitrectomy 

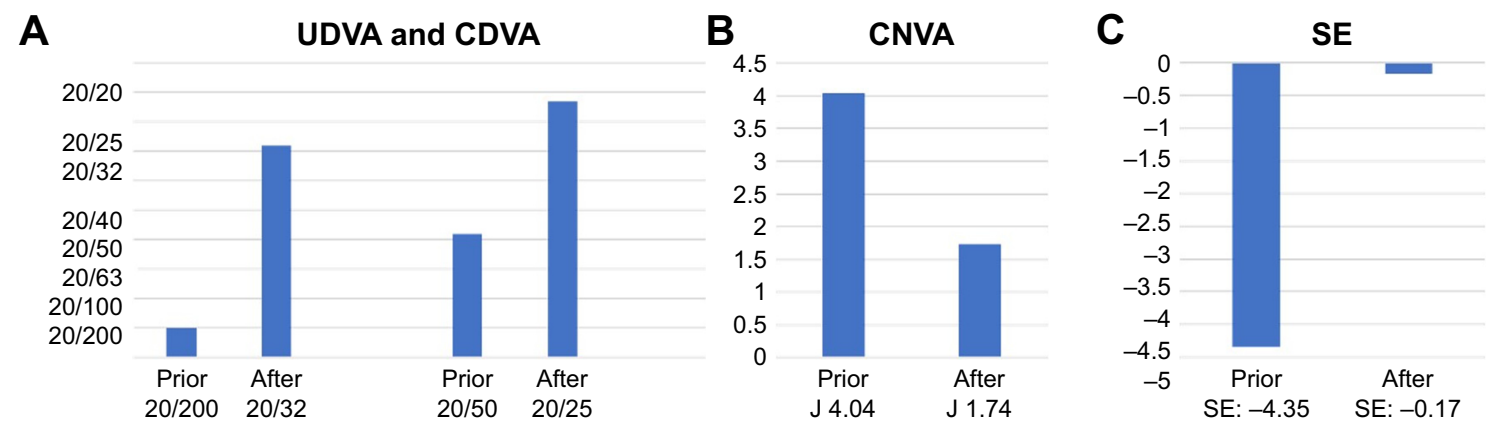

Figure I (A) Mean UDVA and CDVA prior to and after CS $(p<0.00 \mathrm{I})$. (B) Mean CNVA prior to and after CS ( $p<0.00 \mathrm{I})$. (C) Mean SE prior to and after CS ( $p<0.00 \mathrm{I})$. Abbreviations: CDVA, corrected distance visual acuity; CNVA, corrected near visual acuity; CS, cataract surgery; J, Jaeger; SE, spherical equivalent; UDVA, uncorrected distance visual acuity.

cataracts developed relatively quickly in the postoperative period. The high incidence of nuclear sclerosis is consistent with the findings of other studies. ${ }^{1,2,6,18,19}$

An unusually deep anterior chamber during phacoemulsification was first described by $\mathrm{Yeoh}^{20}$ in vitrectomized eyes. This makes CS especially challenging in these cases. Some aspects that may help to prevent fluctuation of the anterior chamber are keeping the infusion bottle low, constructing an accurately sized and clear corneal incision to maintain a relatively sealed chamber during surgery, or adding adrenaline to the infusion solution to keep the pupil dilated. However, with the modern phacoemulsification machines we used, intraoperative miosis was only observed in $7 \%$ of the eyes in our study, in which intracameral mydriatics or iris hooks were successfully used. Capsulorhexis may also be difficult in these eyes because of a very deep anterior chamber and the lack of the counterpressure exercised by the vitreous, especially in myopic eyes ( $45 \%$ of our cases). However, we only had 1 small anterior rhexis tear and 1 eye with transient hyphema because of iris trauma. In eyes with very early cataract development within 4 months after PPV (6 eyes in our study), lens touch with posterior capsule rupture has to be considered. ${ }^{12,21}$ Thus, a thorough hydrodissection, adequate lens rotation, and gentle nucleus manipulation must be performed to avoid unnecessary zonular stress or posterior capsule tears. Fortunately, we did not have any zonular dehiscence or posterior capsule rupture. In a recent study, ${ }^{12}$ the incidence of lens touch after PPV was $3.7 \%$, and during the subsequent CS in this group, $11 \%$ had a posterior capsule rupture.

In the current study, the most frequent postoperative complications were CME and PCO. Postoperative CME was found after a mean time of 42 days, mostly in patients with prior epiretinal membrane. Thus, we recommend performing a macular OCT routinely to detect this complication at an early stage, within 2 months, or in all patients whose vision decreases after surgery. In a recent study, neither CME was noted at 12 weeks follow-up ${ }^{4}$ nor was this observed in a previous case series after 6 weeks follow-up; ${ }^{5}$ however, OCT was not routinely used. PCO was found after a mean of 14 months and Nd:YAG capsulotomy was performed. Some studies found that the incidence of PCO was higher in vitrectomized eyes compared with nonvitrectomized eyes. ${ }^{2,22}$

In our study, significant improvement in uncorrected and corrected distance or near vision was observed postoperatively after phacoemulsification. Although it has been reported that biometry is not always accurate in eyes that have had PPV, ${ }^{4}$ we achieved a final spherical equivalent of -0.17 after CS. VA improved by more than 2 Snellen lines in $91 \%$ of our cases, and $95 \%$ of the eyes achieved VA $\geq 20 / 40$ after CS. However, visual function depended on

Table 4 CDVA prior to and after PPV CS

\begin{tabular}{|c|c|c|c|c|c|c|c|c|}
\hline \multirow{2}{*}{$\begin{array}{l}\text { CDVA } \\
\text { CDVA } \leq 20 / 200\end{array}$} & \multicolumn{2}{|c|}{$\begin{array}{l}\text { CDVA prior } \\
\text { to PPV }\end{array}$} & \multicolumn{2}{|c|}{ CDVA after PPV } & \multicolumn{2}{|c|}{ CDVA prior to CS } & \multicolumn{2}{|c|}{ CDVA after CS } \\
\hline & $n=31$ & $35.6 \%$ & $n=3$ & $3.4 \%$ & $n=11$ & $12.6 \%$ & $\mathrm{n}=0$ & $0 \%$ \\
\hline CDVA 20/200-20/40 & $n=29$ & $33.3 \%$ & $n=19$ & $21.8 \%$ & $n=36$ & $41.4 \%$ & $\mathrm{n}=4$ & $4.6 \%$ \\
\hline$C D V A \geq 20 / 40$ & $n=30$ & $34.5 \%$ & $n=68$ & $78.2 \%$ & $n=43$ & $49.4 \%$ & $n=83$ & $95.4 \%$ \\
\hline CDVA $\geq 2$, Snellen lines & N/A & $N / A$ & $n=64$ & $73.5 \%$ & $N / A$ & N/A & $n=79$ & $90.8 \%$ \\
\hline
\end{tabular}

Abbreviations: CDVA, corrected distance visual acuity; CS, cataract surgery; N/A, not applicable; PPV, pars plana vitrectomy. 


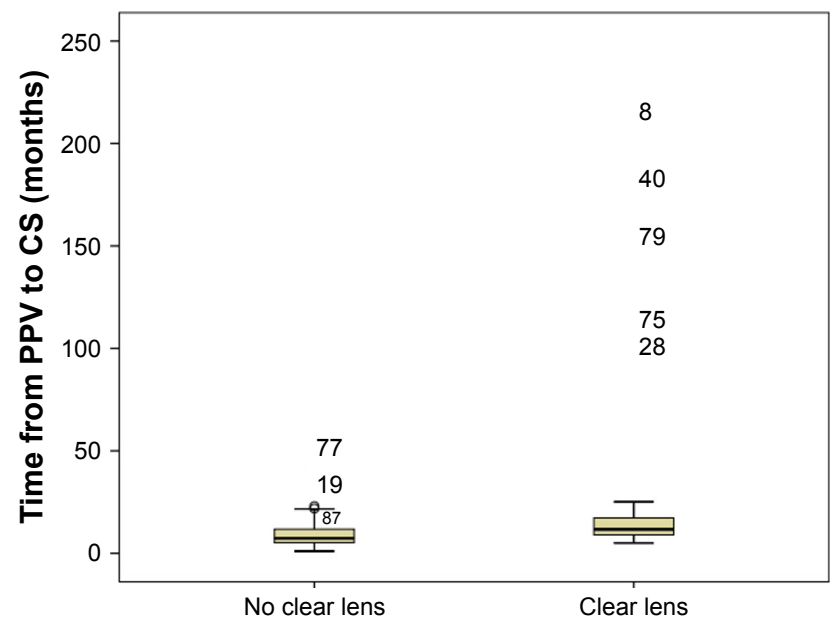

Figure 2 Eyes with clear lens prior to the PPV $(n=45)$ had significantly later CS than eyes with some degree of cataract (27.I vs 9.7 months; $p=0.016$ ).

Abbreviations: CS, cataract surgery; PPV, pars plana vitrectomy.

the underlying retinal disease, and $25 \%$ of our patients had residual symptoms including metamorphopsia, diplopia, or central scotoma after CS.

The development of postvitrectomy cataract appears to be multifactorial. In our study, patients of advanced age with clear lens at PPV had significantly earlier CS than the younger ones with clear lens (12 vs 41 months). Thus, age at PPV may be a risk factor for cataract development after PPV. Thompson reported that vitrectomized eyes of young patients had small increases in nuclear sclerosis ( 0.12 grades/yr) and that eyes of patients of advanced age had substantial progression $(0.81$ grades $/ \mathrm{yr}){ }^{10}$

Eyes with some degree of cataract prior to PPV also significantly influenced the need for cataract removal, and such eyes had earlier CS than eyes with prior clear lens ( $10 \mathrm{vs}$ 27 months). These results are consistent with other studies in which progression of postvitrectomy nuclear sclerosis generally occurred in eyes with a higher degree of preoperative lens opacity. ${ }^{9}$ Thus, lens status at PPV may be a risk factor for cataract development after PPV.

Eyes with gas tamponade were operated on earlier than eyes without tamponade, but this was not statistically significant.

Table 5 Multivariate cox regression analysis for CS

\begin{tabular}{lllllll}
\hline Variables & df & $\begin{array}{l}\text { Parameter } \\
\text { estimate }\end{array}$ & $\begin{array}{l}\text { Standard } \\
\text { error }\end{array}$ & $\chi^{2}$ & p-values & $\begin{array}{l}\text { Hazard } \\
\text { ratio }\end{array}$ \\
\hline Age & I & 0.648 & 0.087 & 4.804 & 0.028 & 1.912 \\
Gas & I & -0.016 & 0.081 & 3.118 & 0.077 & 0.983 \\
Myopia & I & -0.241 & 0.078 & 7.320 & 0.567 & 0.786 \\
Lens status & I & 0.902 & 0.085 & II.I70 & 0.001 & 2.465 \\
\hline
\end{tabular}

Abbreviation: CS, cataract surgery.

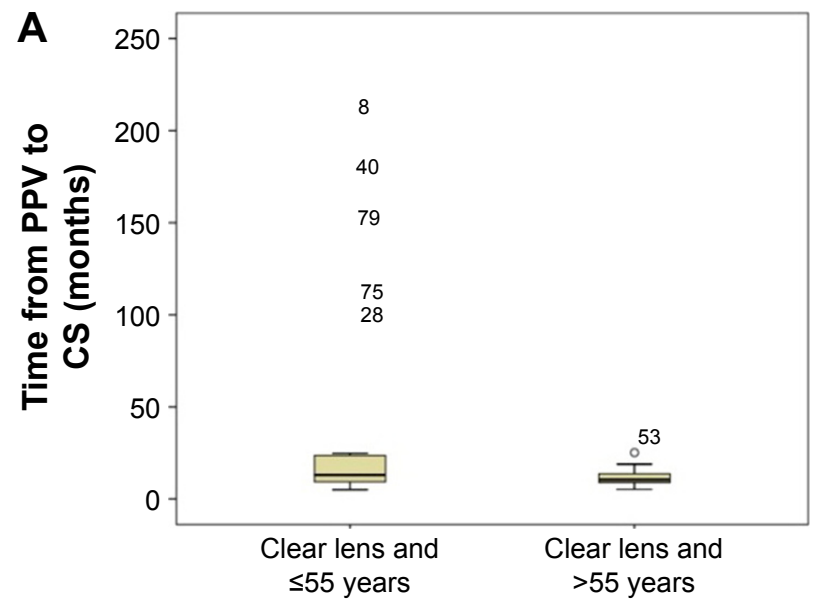

B

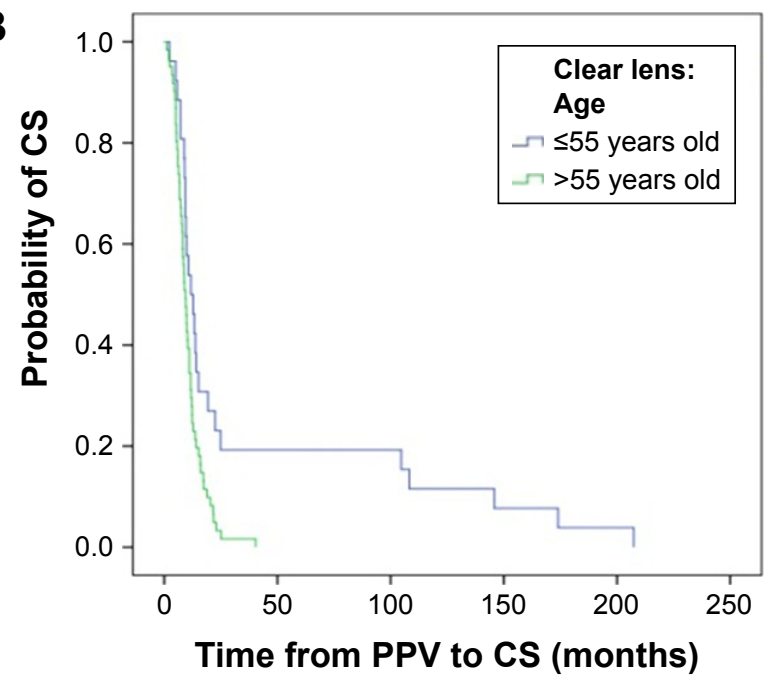

Figure 3 (A) Patients aged $>55$ years with clear lens at PPV $(n=2 I)$ had significantly earlier CS than younger ones with clear lens ( $n=24)$; ( I I.8 vs 40.5 months; $p=0.033$ ). (B) The Kaplan-Meier method and log-rank (Mantel-Cox) test were applied to data for patients with clear lens classified into 2 groups according to age $\leq$ or $>55$ years $(p=0.005)$.

Abbreviations: CS, cataract surgery; PPV, pars plana vitrectomy.

Two previous studies found no effect of intraocular gas bubbles on cataract progression. ${ }^{13,18}$ However, Thompson ${ }^{10}$ found that PPV with gas-fluid exchange was more cataractogenic, with a nuclear sclerosis increase of $60 \%$ compared with eyes without gas.

In addition, in our series, myopia and axial length did not correlate with the time of the CS after PPV. These findings have not been previously reported. Other intraoperative variables, such as the type of infusion fluid, position of the infusion cannula, and the type of light source, remained constant in our study and could not be analyzed.

Limitations of the current study are the retrospective design, the relatively small number of subjects, and the variable follow-up duration. Another limitation is that cataracts were graded subjectively by the surgeon with the slit-lamp rather than by a masked examiner evaluating standard lens photographs. 


\section{Conclusion}

In conclusion, our study demonstrates that patient age and the presence of preoperative nuclear sclerosis are important risk factors in determining the time of cataract development, whereas axial length or the presence of myopia had no effect in vitrectomized eyes. Although eyes with intraocular gas were operated on earlier, this difference was not statistically significant. Thus, the effect of gas is still controversial. Progression of nuclear cataracts leads to substantial visual loss during the first year after vitrectomy in most patients, and surgeons should know the special characteristics of the vitrectomized eyes to prevent complications. Despite being challenging cases, good visual rehabilitation can be expected, limited by the underlying retinal disease, which should be taken into consideration when advising patients.

\section{Disclosure}

The authors report no conflicts of interest in this work.

\section{References}

1. Feng H, Adelman RA. Cataract formation following vitreoretinal procedures. Clin Ophthalmol. 2014;8:1957-1965.

2. Chang MA, Parides MK, Chang S, Braunstein RE. Outcome of phacoemulsification after pars plana vitrectomy. Ophthalmology. 2002; 109(5):948-954.

3. Biro Z, Kovacs B. Results of cataract surgery in previously vitrectomized eyes. J Cataract Refract Surg. 2002;28(6):1003-1006.

4. Titiyal JS, Agarwal E, Angmo D, Sharma N, Kumar A. Comparative evaluation of outcomes of phacoemulsification in vitrectomized eyes: silicone oil versus air/gas group. Int Ophthalmol. 2017;37(3):565-574.

5. Ahfat FG, Yuen CH, Groenewald CP. Phacoemulsification and intraocular lens implantation following pars plana vitretomy: a prospective eye study. Eye. 2003;17(1):16-20.

6. Blodi BA, Paluska SA. Cataract after vitrectomy in young patients. Ophthalmology. 1997;104(7):1092-1095.

7. Margherio RR, Cox MS Jr, Trese MT, Murphy PL, Johnson J, Minor LA. Removal of epimacular membranes. Ophthalmology. 1985;92(8): $1075-1083$
8. Cherfan GM, Michels RG, de Bustros S, Enger C, Glaser BM. Nuclear sclerotic cataract after vitrectomy for idiopathic epiretinal membranes causing macular pucker. Am J Ophthalmol. 1991;111(4):434-438

9. Melberg NS, Thomas MA. Nuclear sclerotic cataract after vitrectomy in patients younger than 50 years of age. Ophthalmology. 1995;102(10): 1466-1471.

10. Thompson JT. The role of patient age and intraocular gas use in cataract progression after vitrectomy for macular holes and epiretinal membranes. Am J Ophthalmol. 2004;137(2):250-257.

11. Blankenship G, Cortez R, Machemer R. The lens and pars plana vitrectomy for diabetic retinopathy complications. Arch Ophthalmol. 1979; 97(7):1263-1267.

12. Elhousseini Z, Lee E, Williamson TH. Incidence of lens touch during pars plana vitrectomy and outcomes from subsequent cataract surgery. Retina. 2016;36(4):825-829.

13. Ogura Y, Takanashi T, Ishigooka H, Ogino N. Quantitative analysis of lens change after vitrectomy by fluorophotometry. Am J Ophthalmol. 1999;111(2): 179-183.

14. Holekamp NM, Shui YB, Beebe D. Lower intraocular oxygen tension in diabetic patients: possible contribution to decreased incidence of nuclear sclerotic cataract. Am J Ophthalmol. 2006;141(6):1027-1032.

15. Holekamp NM, Bai F, Shui YB, Almony A, Beebe DC. Ischemic diabetic retinopathy may protect against nuclear sclerotic cataract. Am J Ophthalmol. 2011;150(4):543.e1-550.e1.

16. Holekamp NM, Shui YB, Beebe DC. Vitrectomy surgery increases oxygen exposure to the lens: a possible mechanism for nuclear cataract formation. Am J Ophthalmol. 2005;139(2):302-310.

17. Rizzo S, Genovesi-Ebert F, Murri S, et al. 25-gauge, sutureless vitrectomy and standard 20-gauge pars plana vitrectomy in idiopathic epiretinal membrane surgery: a comparative pilot study. Graefes Arch Clin Exp Ophthalmol. 2006;244(4):472-479.

18. De Bustros S, Thompson JT, Michels RG, Enger C, Rice TA, Glaser BM. Nuclear sclerosis after vitrectomy for idiopathic epiretinal membranes. Am J Ophthalmol. 1988;105(2):160-164.

19. Hsuan JD, Brown NA, Bron AJ, Patel CK, Rosen PH. Posterior subcapsular and nuclear cataract after vitrectomy. J Cataract Refract Surg. 2001;27(3):437-444.

20. Yeoh R. Phacoemulsification in vitrectomized eyes. J Cataract Refract Surg. 1999;25(8):1038.

21. Sachdev N, Brar GS, Sukhija J, Gupta V, Ram J. Phacoemulsification in vitrectomized eyes: results using a "phaco chop" technique. Acta Ophthalmol. 2009;87(4)382-385.

22. Shaumberg DA, Dana MR, Christen WG, Glynn RJ. A systematic overview of the incidence of posterior capsule opacification. Ophthalmology. 1998;105(7):1213-1221.
Clinical Ophthalmology

\section{Publish your work in this journal}

Clinical Ophthalmology is an international, peer-reviewed journal covering all subspecialties within ophthalmology. Key topics include: Optometry; Visual science; Pharmacology and drug therapy in eye diseases; Basic Sciences; Primary and Secondary eye care; Patient Safety and Quality of Care Improvements. This journal is indexed on

\section{Dovepress}

PubMed Central and CAS, and is the official journal of The Society of Clinical Ophthalmology (SCO). The manuscript management system is completely online and includes a very quick and fair peer-review system, which is all easy to use. Visit http://www.dovepress.com/ testimonials.php to read real quotes from published authors. 